\title{
Predicting Fluid Responsiveness Using Pulse Pressure Variation after Tidal Volume Challenge in Postoperative Patients Receiving Lung Protective Ventilation: A Clinical Trial
}

\section{Pimsai Kunakorn}

Ramathibodi Hospital

Sunthiti Morakul

Ramathibodi Hospital

Tananchai Petnak

Ramathibodi Hospital

Pongsasit Singhatat

Ramathibodi Hospital

Chawika Pisitsak ( $\nabla$ chawika_p@hotmail.com )

Ramathibodi Hospital https://orcid.org/0000-0002-0487-7673

\section{Research article}

Keywords: Pulse pressure variation, Stroke volume variation, Fluid responsiveness, Tidal volume challenge

Posted Date: November 26th, 2019

DOI: https://doi.org/10.21203/rs.2.17736/v1

License: (c) (i) This work is licensed under a Creative Commons Attribution 4.0 International License.

Read Full License 


\section{Abstract}

Background: Lung protective ventilation with low tidal volume is beneficial in patients with intermediate to high risk of postoperative pulmonary complications. However, during low tidal volume ventilation, pulse pressure variation (PPV) and stroke volume variation (SVV) do not predict fluid responsiveness. We aimed to determine whether changes in PPV and SVV after transient increases in tidal volume can predict fluid responsiveness in these patients.

Methods: We recorded 22 measurements from 15 patients who experienced postoperative acute circulatory failure. We performed a tidal volume challenge by transiently increasing tidal volume (VT) from 6 to $8 \mathrm{~mL} / \mathrm{kg}$ (VT6-8), 8 to $10 \mathrm{~mL} / \mathrm{kg}$ (VT8-10), and 6 to $10 \mathrm{~mL} / \mathrm{kg}$ (VT6$10)$ of patients' predicted body weight. The change in PPV $(\triangle P P V)$ at VT6-8 ( $\triangle$ PPV6-8), VT810 ( $\Delta$ PPV8-10), VT6-10 ( $\Delta$ PPV6-10) and the change in SVV ( $\Delta$ SVV) at VT6-8 ( $\Delta$ SVV6-8), VT8$10(\Delta$ SVV8-10), and VT6-10 ( $\Delta$ SVV6-10) were recorded. Patients were classified as fluid responders if there was an increase in stroke volume of more than $10 \%$ after a fluid bolus.

Results: Following the tidal volume challenge, $\Delta \mathrm{PPV}$ and $\Delta \mathrm{SVV}$ failed to predict fluid responsiveness, with areas under the receiver operating characteristic curves (with $95 \%$ confidence intervals) of 0.49 (0.23-0.74), 0.54 (0.29-0.79), 0.52 (0.28-0.77) for $\triangle P P V 6-8, \Delta P P V 8-10$, and $\Delta$ PPV6-10, and $0.55(0.30-0.80), 0.55(0.31-0.80)$, and $0.59(0.34-0.84)$ for $\Delta S V V 6-8, \Delta S V V 8-$ 10 , and $\Delta$ SVV6-10, respectively.

Conclusions: Changes in PPV and SVV after the tidal volume challenge did not predict fluid responsiveness in postoperative patients with low tidal volume ventilation. Trial registration: This trial was registered with Clinicaltrials.in.th, TCTR20190808003.

\section{Introduction}

Patients with intermediate to high risk of postoperative pulmonary complications (PPCs) should be ventilated with low tidal volume $[1,2]$. Evidence shows that conventional mechanical ventilation with a tidal volume of $10-12 \mathrm{~mL} / \mathrm{kg}$ is associated with higher inflammatory mediators [3, 4]. Therefore, we encourage a low tidal volume ventilation of $6-8 \mathrm{~mL} / \mathrm{kg}$ of predicted body weight in patients with intermediate to high risk of PPCs.

Pulse pressure variation (PPV) and stroke volume variation (SVV) have been widely used to assess fluid responsiveness based on heart-lung interactions. When using these parameters, the tidal volume must be at least $8 \mathrm{~mL} / \mathrm{kg}$ to result in cyclic changes in stroke volume during respiration $[5,6]$. When patients are ventilated with a low tidal volume of $6 \mathrm{~mL} / \mathrm{kg}$, the effect of intrathoracic pressure is insufficiently high to see variations in PPV and SVV, even when patients are fluid-responsive [7]. Therefore, several studies have been performed to assess fluid responsive in this group of patients. One technique in these studies is called the "tidal volume challenge", which is a maneuver that increases tidal volume from 6 to $8 \mathrm{~mL} / \mathrm{kg}$ of predicted body weight and assesses the increase in PPV and SVV. Previous studies found that the tidal 
volume challenge predicted fluid responsiveness $[8,9]$. In this study, we analyzed the ability of the change in PPV $(\triangle \mathrm{PPV})$ and SVV $(\Delta \mathrm{SVV})$ after tidal volume challenge to assess fluid responsiveness in patients receiving low tidal volume ventilation after surgery. We also increased changing the tidal volume to 10 $\mathrm{mL} / \mathrm{kg}$ of predicted body weight, which differed from previous studies.

\section{Materials And Methods}

This study was performed at the surgical ICU of our institution after obtaining written informed consent from all patients or their substitute decision makers. The protocol was approved by the Ramathibodi Institutional Review Board.

\section{Study Population}

We included adult surgical patients who received lung protective ventilation with a low tidal volume of $6 \mathrm{~mL} / \mathrm{kg}$ of predicted body weight because of a moderate to high risk of PPCs according to their Assess Respiratory Risk in Surgical Patients in Catalonia scores [10, 11]. All patients required a preload assessment because of shock defined by one of the following: mean arterial pressure $<65$ $\mathrm{mmHg}$, systolic blood pressure $<90 \mathrm{mmHg}$, a decrease in systolic blood pressure $>40 \mathrm{mmHg}$ from baseline, arterial blood lactate $\geq 4 \mathrm{mmol} / \mathrm{L}$, and/or urine output $<0.5 \mathrm{~mL} / \mathrm{kg} / \mathrm{hour}$ for at least 1 hour. Patients with contraindications to the use of PPV or SVV were excluded, such as patients with arrhythmias, right heart failure, valvular heart disease, heart rate/respiratory rate ratio $<3.6$, or abdominal compartment syndrome.

\section{Outcomes}

The primary outcome of this study was the sensitivity and specificity of PPV and SVV to identify fluid responsiveness after tidal volume challenge. The secondary outcomes were the optimal cutoffs for $\triangle \mathrm{PPV}$ and $\triangle \mathrm{SVV}$ after the tidal volume challenge to detect fluid responsiveness.

\section{Methods}


All patients who met the inclusion criteria were deeply sedated to allow ventilator synchronization, with some patients receiving neuromuscular blocking agents. We measured stroke volume and SVV by pulse contour analysis (FloTrac/EV1000 ${ }^{\mathrm{TM}}$; Edwards Lifesciences, Irvine, CA). PPV was measured using a Philips IntelliVue MX700 (Philips Medical Systems Boeblingen GmbH, Boeblingen, Germany). Stroke volume, cardiac output, PPV, and SVV were measured at baseline and after the tidal volume challenge. The tidal volume challenge was performed by increasing the tidal volume from 6 to $8 \mathrm{~mL} / \mathrm{kg}$ and from 8 to $10 \mathrm{~mL} / \mathrm{kg}$ of predicted body weight. If the plateau pressure was $>30 \mathrm{cmH}_{2} \mathrm{O}$, we decreased the tidal volume to $6 \mathrm{~mL} / \mathrm{kg}$ and excluded the patient from the study. Stroke volume, cardiac output, SVV, and PPV were measured 1 minute after each step. Finally, $500 \mathrm{~mL}$ of crystalloid fluids was infused over 30 minutes to classify a patient's fluid responsive status, which was defined as a $10 \%$ increase in stroke volume from baseline. Details of the procedures are shown in Figure 1.

\section{Statistical Analysis}

Continuous variables were presented with mean \pm standard deviation or median (interquartile range). Categorical variables were presented as number (percentage). We compared categorical variables using the Chi-square test or Fisher's exact test. Normally-distributed quantitative variables were compared using the t-test, and other quantitative variables were compared using the Mann-Whitney $U$ test. The areas under the receiver operating characteristic curves for fluid responsiveness were calculated. The optimal cutoff points for $\triangle \mathrm{PPV}$ and $\triangle \mathrm{SVV}$ were the values that maximized the weighted combination of sensitivity and specificity. $P<0.05$ was considered statistically significant. All statistical analysis were performed using SPSS software, version 24 for Windows (IBM Corp., Armonk, NY).

\section{Results}

Fifteen patients were included in this study. Two of the measurements were excluded during the tidal volume challenge because of life-threatening hypotension and the development of a new arrhythmia, leaving a total of 20 measurements. We divided the 20 measurements into responders and nonresponders: 11 responders and 9 nonresponders.

Patients' characteristics did not differ significantly between responders and nonresponders (Table 1). Baseline respiratory parameters also did not differ between responders and nonresponders (Table 2). Plateau pressure was significantly higher from tidal volume 6 to $8 \mathrm{~mL} / \mathrm{kg}$ and from 8 to $10 \mathrm{~mL} / \mathrm{kg}$ in both responders and nonresponders, but static respiratory compliance did not differ during the tidal volume challenge in either group (Table 3). Stroke volume before and after fluid loading were $59.1 \pm 22.0$ and $70.0 \pm 27.3 \mathrm{~mL}$ for responders and $50.9 \pm 17.0$ and $51.9 \pm 16.7 \mathrm{~mL}$ for nonresponders. 
Baseline PPV and SVV values at tidal volume $6 \mathrm{~mL} / \mathrm{kg}$ were in grey zone, and other hemodynamic parameters did not differ between responders and nonresponders (Table 2). After the tidal volume challenge, we saw no significant difference between $\triangle P P V$ and $\triangle \mathrm{SVV}$ between responders and nonresponders at each step of the tidal volume challenge (Table 4). The areas under the receiver operating characteristic curves (with 95\% confidence intervals) were: $0.4(0.2-0.7), 0.5(0.2-0.7)$, and 0.5 $(0.2-0.7)$ for $\Delta \mathrm{PPV}_{6-8}, \Delta \mathrm{PPV}_{8-10}$, and $\Delta \mathrm{PPV}_{6-10}$ (Fig. $\left.2 \mathrm{~A}\right)$, and $0.5(0.3-0.8), 0.5(0.3-0.8)$, and $0.5(0.3-$ $0.8)$ for $\Delta S V_{6-8}, \Delta S V_{8-10}$, and $\Delta S V_{6-10}$, respectively (Fig. $2 B$ ). The results showed that the tidal volume challenge did not discriminate fluid responders from nonresponders.

\section{Discussion}

PPV and SVV have been widely used to predict fluid responsiveness based on heart-lung interaction. The principle of heart-lung interaction is that cyclic changes in intrathoracic pressure and transpulmonary pressure affect cardiac preload. Therefore, these effects can be seen when ventilating with a sufficient tidal volume of at least $8 \mathrm{~mL} / \mathrm{kg}$ of predicted body weight [12]. During low tidalvolume ventilation, PPV and SVV may be falsely low because the tidal volume may be insufficient to produce a significant change in intrathoracic pressure $[13,14]$. Therefore, it is recommended to use a tidal volume of at least $8 \mathrm{~mL} / \mathrm{kg}$ with cutoff points for static SVV and PPV of $10 \%$ and $13 \%$, respectively. In some situations, a tidal volume of $8 \mathrm{~mL} / \mathrm{kg}$ might injure the lungs; therefore, we reduced tidal volume to $6 \mathrm{~mL} / \mathrm{kg}$, which resulted in the inability of SVV and PPV to predict fluid responsiveness. For example, patients with acute respiratory distress syndrome (ARDS) who received lung-protective ventilation have been excluded from studies using PPV and SVV to predict fluid responsiveness because of the decrease in transmission of intrathoracic pressure to the cardiovascular system [15]. However, Myatra et al. demonstrated that in patients with ARDS with low tidal volume ventilation, a tidal volume challenge from 6 to $8 \mathrm{~mL} / \mathrm{kg}$ predicted fluid responders with larger areas under the receiver operating characteristic curves compared with using static PPV and SVV at a tidal volume of $8 \mathrm{~mL} / \mathrm{kg}$; the cutoff values were $3.5 \%$ and $2.5 \%$, respectively. Jun et al. also demonstrated the predictive ability of a tidal volume challenge from 6 to 8 $\mathrm{mL} / \mathrm{kg}$ in robotic-assisted laparoscopic surgery in the Trendelenburg position, with cutoff values of $1 \%$ for $\triangle P P V$ and $2 \%$ for $\Delta S V V$ [9]. Messina et al. performed a tidal volume challenge from 6 to $8 \mathrm{~mL} / \mathrm{kg}$ in elective neurosurgery and found that tidal volume challenge predicted fluid responsiveness with cutoff values of $13.3 \%$ for PPV and $12.1 \%$ for SVV [16]. Additional previous studies illustrated the ability of tidal volume challenge to predict fluid responsiveness, using variable cutoff values. The main factor explaining these different cutoff values may be differences in patients' chest wall compliance. Liu et al. inserted esophageal balloons in patients with ARDS and found that pleural pressure change $(\triangle \mathrm{Ppl})$ was the most important determinant of PPV among other respiratory variables (plateau pressure, change in airway pressure, tidal volume, respiratory elastance, $\triangle \mathrm{Ppl}$, and chest wall elastance/respiratory elastance (Ecw/ERS)) in both responders and nonresponders [17]. Moreover, the authors emphasized that $\Delta \mathrm{Ppl}$ was attenuated primarily by a low Ecw/ERS ratio and, to a lesser extent, by low tidal volume. Therefore, PPV and SVV in patients with low Ecw/ERS was less reliable than in patients with a high Ecw/ERS, with a 
proposed cutoff of 0.28 , according to Liu et al.'s study, and tidal volume challenge in low Ecw might result in an insufficient increase in $\triangle \mathrm{Ppl}$.

In the present study, we performed tidal volume challenge in patients with intermediate to high risk of PPCs receiving lung-protective ventilation using a tidal volume of $6 \mathrm{~mL} / \mathrm{kg}$ of predicted body weight. To our knowledge, this is the first study to evaluate increasing tidal volume from 6 to $8 \mathrm{~mL} / \mathrm{kg}$ and then from 8 to $10 \mathrm{~mL} / \mathrm{kg}$, to maximize the efficacy of the tidal volume challenge. We found different results compared with previous studies, and we hypothesized that tidal volume challenges using increases from 6 to $8 \mathrm{~mL} / \mathrm{kg}, 8$ to $10 \mathrm{~mL} / \mathrm{kg}$, and 6 to $10 \mathrm{~mL} / \mathrm{kg}$ did not cause adequate pleural pressure change. Because our patient population constituted postoperative patients with intermediate to high risk of PPCs (primarily atelectasis), the average respiratory compliance was $38.2 \pm 9.7 \mathrm{~mL} / \mathrm{cmH}_{2} \mathrm{O}$; therefore, more than half of the patients had values below the normal range. Atelectasis might have caused decreased lung compliance in our patients. We assumed that our patients had normal chest wall compliance according to results from previous studies evaluating low chest wall compliance; for example, our patients were not obese or septic, and the administered perioperative fluid volume was less than $3 \mathrm{~L}$ [18]. Our patients might have had normal or good chest wall compliance, but low respiratory compliance from increased lung stiffness secondary to atelectasis; therefore, the usefulness of the tidal volume challenge was limited in these patients. Differences in the cutoff values reported after tidal volume challenges in different studies may be explained by differences in patients' chest wall and respiratory elastance, which were not measured in our study. Messina et al. reported much higher cutoff values after the tidal volume challenge compared with the studies of Myatra et al. and Jun et al. [8, 9]. Patients from Messina et al.'s study underwent cranial surgery and had an average respiratory compliance of $65[58-73] \mathrm{mL} / \mathrm{cmH}_{2} \mathrm{O}$, suggesting that the sensitivity of the tidal volume challenge was lower in patients with good respiratory compliance. We concluded that a change of 2 or $4 \mathrm{~mL} / \mathrm{kg}$ of tidal volume from baseline might not cause sufficient changes in pleural pressure to affect cardiac preload, especially in patients with good chest wall compliance and low total respiratory compliance.

The main limitation of this study is that we did not measure pleural pressure change; therefore, our conclusion regarding the inability of the tidal volume challenge to predict fluid responsiveness in this study was based on knowledge from previous studies. Another limitation is that we intermittently administered sedative agents during the procedure, which might have induced cardiovascular effects; for instance, vasodilatation. As a result, the interval between the beginning of the study and the fluid loading to identify fluid responsiveness might be a confounder because of changes in fluid responsive status related to the sedative drugs. This limitation can be minimized by performing the tidal volume challenge under constant-level sedation or anesthesia.

\section{Conclusion}

Changes in PPV and SVV after the tidal volume challenge did not predict fluid responsiveness in postoperative patients with low tidal volume ventilation. Future studies including pleural pressure 
measurements after the tidal volume challenge in postoperative patients are needed to fully explain our findings.

\section{Declarations}

\section{Ethics approval and consent to participate}

The study was approved by the Medical Ethics Committee of Ramathibodi Hospital (10-60-65). Written informed consents were obtained from all patients or their representatives.

\section{Availability of data and materials}

The datasets used and/or analysed during the current study are available from the corresponding author on reasonable request.

\section{Competing interests}

The authors declare that they have no competing interest.

\section{Funding}

This study was funded by a grant from Ramathibodi Hospital.

\section{Authors' contributions}

Pimsai Kunakorn - Research design, research investigator, data collection, data analysis, manuscript drafting.

Sunthiti Morakul - Research methodology, interpretation of data, manuscript revision 
Tananchai Petnak - Interpretation of data, manuscript revision

Pongsasit Singhatat - Manuscript revision

Chawika Pisitsak - Principal investigator, research design, statistical analysis, manuscript revision.

All authors have reviewed the manuscript and approved the submitted version.

\section{Acknowledgements}

We acknowledge the medical care team at surgical ICU for their support in this study.

\section{References}

1. Serpa Neto A, Cardoso SO, Manetta JA, Pereira VG, Esposito DC, Pasqualucci Mde O, et al. Association between use of lung-protective ventilation with lower tidal volumes and clinical outcomes among patients without acute respiratory distress syndrome: a meta-analysis. JAMA. 2012;308:1651-9.

2. Futier E, Constantin JM, Paugam-Burtz C, Julien P, Mathilde E, Arthur N, et al. A trial of intraoperative low tidal volume ventilation in abdominal surgery. N Engl J Med. 2013;369:428-37.

3. Zupancich E, Paparella D, Turani F, Munch C, Rossi A, Massaccesi S, et al. Mechanical ventilation affects inflammatory mediators in patients undergoing cardiopulmonary bypass for cardiac surgery: a randomized clinical trial. J Thorac Cardiovasc Surg. 2005;130:378-83.

4. Michelet P, D-Journo X-B, Roch A, Doddoli C, Marin V, Papazian L, et al. Protective ventilation influences systemic inflammation after esophagectomy: a randomized controlled study. Anesthesiology. 2006;105:911-9.

5. De Backer D, Heenen S, Piagnerelli M, Koch M, Vincent J-L. Pulse pressure variations to predict fluid responsiveness: influence of tidal volume. Intensive Care Med. 2005;31:517-23.

6. Marik PE, Cavallazzi R, Vasu T, Hirani A. Dynamic changes in arterial waveform derived variables and fluid responsiveness in mechanically ventilated patients: a systematic review of the literature. Crit Care Med. 2009;37:2642-7.

7. Monnet X, Marik PE, Teboul J-L. Prediction of fluid responsiveness: an update. Ann Intensive Care. 2016;6:111.

8. Myatra SN, Prabu NR, Divatia JV, Monnet X, Kulkarni AP, Teboul J-L. The changes in pulse pressure variation or stroke volume variation after a "Tidal Volume Challenge" reliably predict fluid responsiveness during low tidal volume ventilation. Crit Care Med. 2017;45:415-21. 
9. Jun J-H, Chung RK, Baik HJ, Chung MH, Hyeon J-S, Lee Y-G, et al. The tidal volume challenge improves the reliability of dynamic preload indices during robot-assisted laparoscopic surgery in the Trendelenburg position with lung-protective ventilation. BMC Anesthesiol. 2019;19:142.

10. Sabate S, Canet J, Gallart L, de Abreu MG, Belda J, Langeron O, et al. Prospective external validation of a predictive score for postoperative pulmonary complications. Anesthesiology. 2014;121:219-31.

11. Canet J, Gallart L, Gomar C, Paluzie G, Vallès J, Castillo J, et al. Prediction of postoperative pulmonary complications in a population-based surgical cohort. Anesthesiology. 2010;113:1338-50.

12. De Backer D, Heenen S, Piagnerelli M, Koch M, Vincent JL. Pulse pressure variations to predict fluid responsiveness: influence of tidal volume. Intensive Care Med. 2005;31:517-23.

13. Reuter DA, Bayerlein J, Goepfert MSG, Weis FC, Kilger E, Lamm P, et al. Influence of tidal volume on left ventricular stroke volume variation measured by pulse contour analysis in mechanically ventilated patients. Intensive Care Med. 2003;29:476-80.

14. De Backer D, Heenen S, Piagnerelli M, Koch M, Vincent J-L. Pulse pressure variations to predict fluid responsiveness: influence of tidal volume. Intensive Care Med. 2005;31:517-23.

15. Jardin F, Genevray B, Brun-Ney D, Bourdarias J-P. Influence of lung and chest wall compliances on transmission of airway pressure to the pleural space in critically ill patients. Chest. 1985;88:653-8.

16. Messina A, Montagnini C,Cammarota G, De Rosa S, Giuliani F, Muratore L, et al. Tidal volume challenge to predict fluid responsiveness in the operating room: An observational study. Eur $\mathrm{J}$ Anaesthesiol. 2019;36:583-91

17. Liu Y, Wei LQ, Li GQ, Yu X, Li GF, Li YM. Pulse pressure variation adjusted by respiratory changes in pleural pressure, rather than by tidal volume, reliably predicts fluid responsiveness in patients with acute respiratory distress syndrome. Crit Care Med. 2016;44:342-51.

18. Murphy PB, Parry NG, Sela N, Leslie K, Vogt K, Ball I. Intra-abdominal hypertension is more common than previously thought. Crit Care Med. 2018;46:958-64.

\section{Tables}

Table 1 Patients' Characteristics 


\begin{tabular}{|c|c|c|c|c|}
\hline Variable & All patients & $\begin{array}{l}\text { Responders } \\
\mathrm{N}=11\end{array}$ & $\begin{array}{c}\text { Nonresponders } \\
\mathrm{N}=9\end{array}$ & $\begin{array}{c}\mathrm{P}- \\
\text { value }\end{array}$ \\
\hline Age (y) & $60.5(51.7-68.2)$ & $60.7 \pm 9.7$ & $62.0 \pm 11.0$ & 0.76 \\
\hline Male sex & $7(58.3)$ & 7 (63.3) & 7 (63.6) & 1.00 \\
\hline BMI $\left(\mathrm{kg} / \mathrm{m}^{2}\right)$ & $22.6(19.1-26.0)$ & $\begin{array}{l}20.0(18.7- \\
24.6)\end{array}$ & $\begin{array}{l}21.2(18.7- \\
22.7)\end{array}$ & 1.00 \\
\hline APACHE II score & $20.5(14.5-27.0)$ & $\begin{array}{l}20.0(14.0- \\
24.0)\end{array}$ & $\begin{array}{l}18.0(14.0- \\
28.0)\end{array}$ & 0.94 \\
\hline ASA physical status $\geq 3$ & $11(91.6)$ & $9(81.8)$ & $11(100)$ & 0.47 \\
\hline $\begin{array}{l}\text { ARISCAT Score for } \\
\text { PPCs }\end{array}$ & $\begin{array}{l}39.5(28.75- \\
55.75)\end{array}$ & $40(26-59)$ & $39(37-68)$ & 0.60 \\
\hline \multicolumn{5}{|l|}{ Comorbidities } \\
\hline Hypertension & $7(58.30)$ & $6(54.5)$ & $7(63.6)$ & 1.00 \\
\hline Diabetes mellitus & $6(50.00)$ & $3(27.2)$ & $7(63.6)$ & 0.08 \\
\hline Stroke & $3(25.00)$ & $4(36.3)$ & $2(18.1)$ & 0.63 \\
\hline COPD & $3(25.00)$ & $2(18.1)$ & $4(36.3)$ & 0.63 \\
\hline \multicolumn{5}{|l|}{ Laboratory variables } \\
\hline Lactate & $11.0 \pm 3.4$ & $1.7(0.5-7.0)$ & $3.80(2.2-5.8)$ & 0.43 \\
\hline \multicolumn{5}{|l|}{ Surgery } \\
\hline $\begin{array}{l}\text { Gastrointestinal } \\
\text { surgery }\end{array}$ & $6(50 \%)$ & $6(54.5)$ & $6(54.5)$ & 1.00 \\
\hline Neurosurgery & $2(16.6 \%)$ & $1(9.0)$ & $1(9.0)$ & 1.00 \\
\hline Vascular surgery & $2(16.6 \%)$ & $2(18.1)$ & $1(9.0)$ & 1.00 \\
\hline Gynecological surgery & $1(8.3 \%)$ & $0(0)$ & $3(27.2)$ & 0.21 \\
\hline Plastic surgery & $1(8.3 \%)$ & $2(18.1)$ & $0(0)$ & 0.47 \\
\hline \multicolumn{5}{|l|}{ Perioperative data } \\
\hline Crystalloids (mL/h) & $794.7 \pm 439.3$ & $813.5 \pm 567.7$ & $770.5 \pm 245.1$ & 0.82 \\
\hline Urine output (mL/kg/h) & $0.6(0.0-1.8)$ & $0.2(0.2-4.6)$ & $0.2(0.0-1.5)$ & 0.43 \\
\hline
\end{tabular}

Results are expressed as the median (25\%-75\%) or mean \pm standard deviation or number (\%). ASA, American Society of Anesthesiologists classification; BMI, body mass index; ARISCAT, Assess Respiratory Risk in Surgical Patients in Catalonia; COPD, chronic obstructive pulmonary disease; PPCs, postoperative pulmonary complications; APACHE, Acute Physiology and Chronic Health Evaluation II

Table 2 Patients' Baseline Respiratory and Hemodynamic Parameters 


\begin{tabular}{|l|l|l|l|l|}
\hline Variable & $\begin{array}{l}\text { All } \\
\mathrm{N}=12\end{array}$ & $\begin{array}{l}\text { Responders } \\
\text { N=11 }\end{array}$ & $\begin{array}{l}\text { Nonresponders } \\
\text { N=9 }\end{array}$ & $\begin{array}{l}\text { P- } \\
\text { value }\end{array}$ \\
\hline $\mathrm{PaO}_{2} / \mathrm{FiO}_{2}$ ratio & $310.5 \pm 187.2$ & $\begin{array}{l}400(262- \\
514)\end{array}$ & $350(157-360)$ & 0.24 \\
\hline Plateau pressure $\left(\mathrm{cmH}_{2} \mathrm{O}\right)$ & $17.1 \pm 5.0$ & $15.7 \pm 2.6$ & $17.4 \pm 5.9$ & 0.39 \\
\hline $\begin{array}{l}\text { Static respiratory compliance } \\
\left(\mathrm{mL} / \mathrm{cmH}_{2} \mathrm{O}\right)\end{array}$ & $38.2 \pm 9.7$ & $39.0 \pm 10.9$ & $37.9 \pm 10.8$ & 0.98 \\
\hline Mean arterial pressure $(\mathrm{mmHg})$ & $76.4 \pm 11.4$ & $79.2 \pm 13.4$ & $74.4 \pm 9.6$ & 0.31 \\
\hline Heart rate $(\mathrm{bpm})$ & $98.8 \pm 19.8$ & $93.7 \pm 22.0$ & $96.9 \pm 18.5$ & 0.71 \\
\hline Lactate & $11.0 \pm 3.4$ & $\begin{array}{l}1.7(0.5- \\
7.0)\end{array}$ & $3.8(2.2-5.8)$ & 0.43 \\
\hline PPV & $12.0 \pm 6.5$ & $10.6 \pm 6.5$ & $10.1 \pm 6.2$ & 0.86 \\
\hline SVV & $10.6 \pm 5.0$ & $10.9 \pm 7.4$ & $9.8 \pm 3.3$ & 0.66 \\
\hline SV & $52.5 \pm 18.9$ & $57.3 \pm 19.8$ & $51.6 \pm 17.8$ & 0.48 \\
\hline
\end{tabular}

Results are expressed as the median (25\%-75\%) or mean \pm standard deviation. $\mathrm{PaO}_{2} / \mathrm{FiO}_{2}$, arterial partial pressure of oxygen/fraction of inspired oxygen; bpm, beats per minute; PPV, pulse pressure variation; SVV, stroke volume variation; SV, stroke volume

Table 3 Patients' Respiratory and Hemodynamic Parameters during each Step of the Tidal Volume Challenge

\begin{tabular}{|l|l|l|l|}
\hline Variables & $\begin{array}{l}\text { Tidal volume } \\
6 \mathrm{~mL} / \mathrm{kg}\end{array}$ & $\begin{array}{l}\text { Tidal volume } \\
8 \mathrm{~mL} / \mathrm{kg}\end{array}$ & $\begin{array}{l}\text { Tidal volume } \\
10 \mathrm{~mL} / \mathrm{kg}\end{array}$ \\
\hline Plateau pressure \\
\hline Responders & $15.7 \pm 2.6$ & $19.0 \pm 6.7^{*}$ & $22.4 \pm 5.7^{* *}$ \\
\hline Nonresponders & $17.4 \pm 5.9$ & $20.6 \pm 6.7^{\square}$ & $23.0 \pm 6.7^{\mathrm{X}}$ \\
\hline Static respiratory compliance \\
\hline Responders & $39.0 \pm 10.9$ & $40.4 \pm 10.0$ & $41.1 \pm 10.4$ \\
\hline Nonresponders & $37.9 \pm 10.8$ & $39.7 \pm 8.1$ & $40.1 \pm 9.3$ \\
\hline Heart rate \\
\hline Responders & $93.7 \pm 22.0$ & $93.9 \pm 22.2$ & $90.9 \pm 20.1$ \\
\hline Nonresponders & $96.9 \pm 18.5$ & $97.0 \pm 19.5$ & $94.9 \pm 17.4$ \\
\hline Mean arterial pressure & $79.7 \pm 11.5$ & $78.8 \pm 10.0$ \\
\hline Responders & $79.7 \pm 13.0$ & $70.8 \pm 18.7$ \\
\hline Nonresponders & $74.7 \pm 9.6$ & $72.8 \pm 5.1$ & $70.0 \pm 1$ \\
\hline Stoke volume & $57.3 \pm 19.8$ & $58.2 \pm 21.9$ & $57.7 \pm 23.0$ \\
\hline Responders & $51.6 \pm 17.8$ & $50.5 \pm 17.8$ & $50.6 \pm 18.2$ \\
\hline Nonresponders & 51.8
\end{tabular}

${ }^{*} \mathrm{P}<0.05$ compared with VT $6 \mathrm{~mL} / \mathrm{kg}$ between responders

${ }^{* *} \mathrm{P}<0.05$ compared with VT $8 \mathrm{~mL} / \mathrm{kg}$ between responders

${ }^{\square} \mathrm{p}<0.05$ compared with VT $6 \mathrm{~mL} / \mathrm{kg}$ between nonresponders

$\mathrm{X}_{\mathrm{p}}<0.05$ compared with VT $8 \mathrm{~mL} / \mathrm{kg}$ between nonresponders

Table 4 Pulse Pressure Variation, Stroke Volume Variation, and Stroke Volume after Tidal Volume Challenge 


\begin{tabular}{|l|l|l|l|}
\hline Variables & $\begin{array}{l}\text { Tidal volume } \\
6 \mathrm{~mL} / \mathrm{kg}\end{array}$ & $\begin{array}{l}\text { Tidal volume } \\
8 \mathrm{~mL} / \mathrm{kg}\end{array}$ & $\begin{array}{l}\text { Tidal volume } \\
10 \mathrm{~mL} / \mathrm{kg}\end{array}$ \\
\hline$\Delta \mathrm{PPV}$ & $2.8 \pm 3.5$ & $4.4 \pm 3.3^{*}$ & $7.2 \pm 3.5^{* *}$ \\
\hline Responders & $3.1 \pm 2.8$ & $3.9 \pm 3.8^{*}$ & $7.0 \pm 3.6^{* *}$ \\
\hline Nonresponders & 3 & \\
\hline$\Delta$ SVV & $-0.5 \pm 3.4^{*}$ & $0.3 \pm 5.3^{* *}$ \\
\hline Responders & $0.9 \pm 3.8$ & $-1 \pm 4.3^{* *}$ \\
\hline Nonresponders & $-1.1 \pm 3.4$ & $0.1 \pm 4.7$ & \\
\hline$\Delta$ SV & $-0.5 \pm 3.4$ & $0.3 \pm 5.3$ \\
\hline Responders & $0.9 \pm 3.8$ & -1.3 & $-1 \pm 4.3$ \\
\hline Nonresponders & $-1.1 \pm 3.4$ & $0.09 \pm 4.7$ &
\end{tabular}

$* * \mathrm{P}<0.05$ compared with VT $6-8 \mathrm{~mL} / \mathrm{kg}$

$* \mathrm{p}<0.05$ compared with VT $6-10 \mathrm{~mL} / \mathrm{kg}$

$+\mathrm{p}<0.05$ compared with before loading

VT, tidal volume; $\Delta \mathrm{PPV}$, change in pulse pressure volume; $\Delta \mathrm{SVV}$, change in stroke volume variation; $\Delta \mathrm{SV}$, change in stroke volume

\section{Figures}

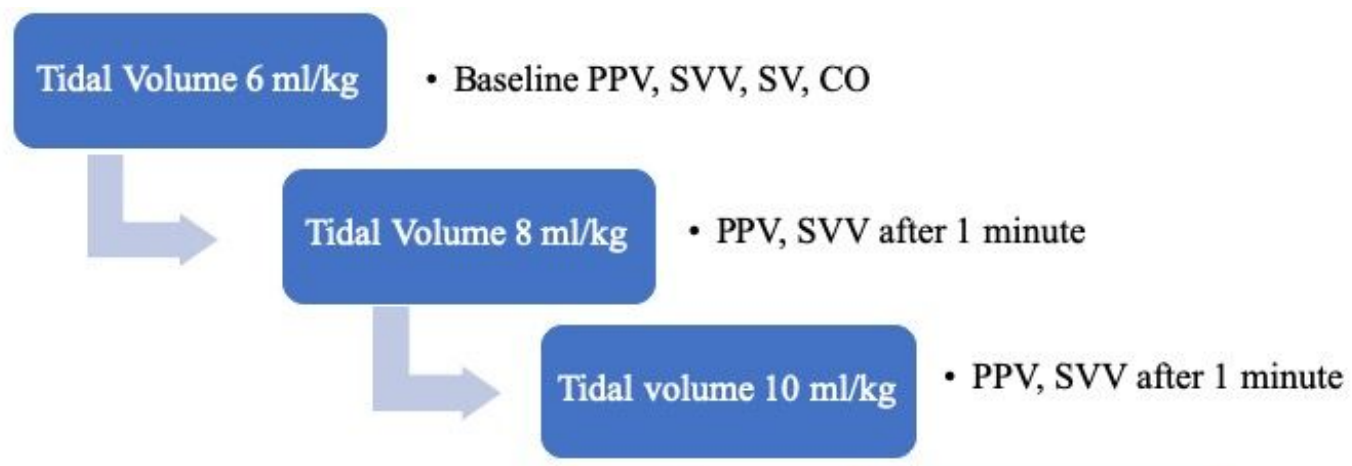

Before the beginning of the protocol, deep sedation was

Tidal volume $6 \mathrm{ml} / \mathrm{kg}$ provided by midazolam or propofol with or without cisatracurium.

\section{Figure 1}

Protocol flow chart 


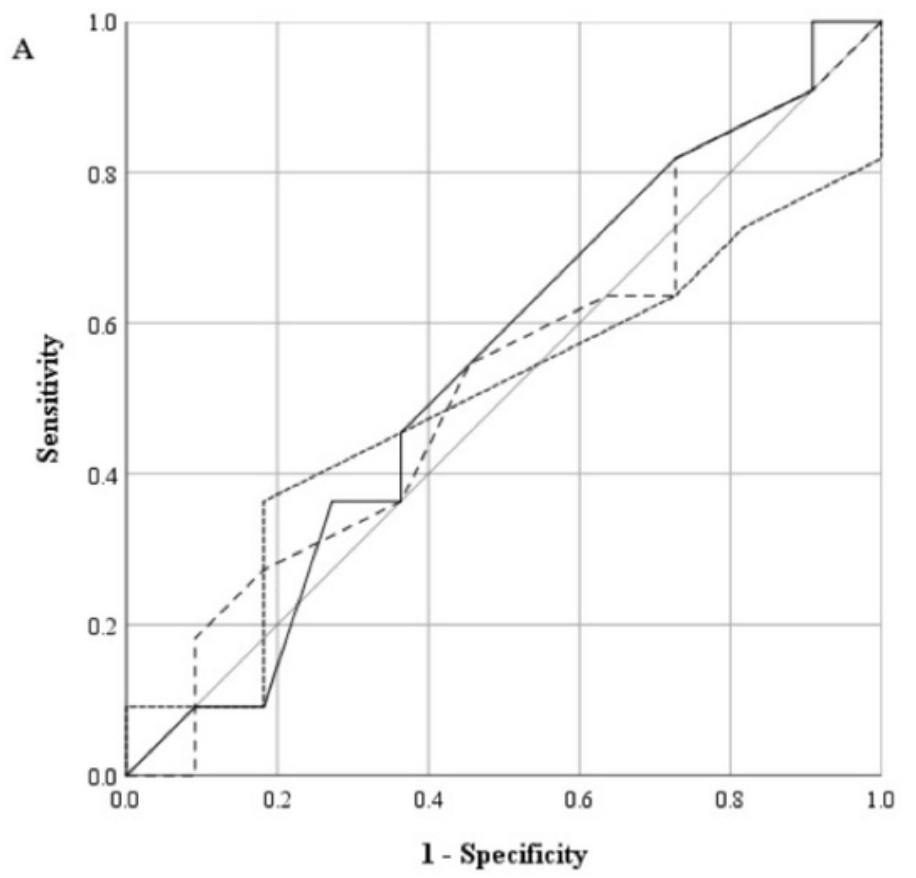

\section{Source of the Curve \\ --- $\triangle$ PPV6-8 \\ $-\triangle \mathrm{PPV} 8-10$ \\ $---\triangle$ PPV6-10 \\ - Reference Line}

B

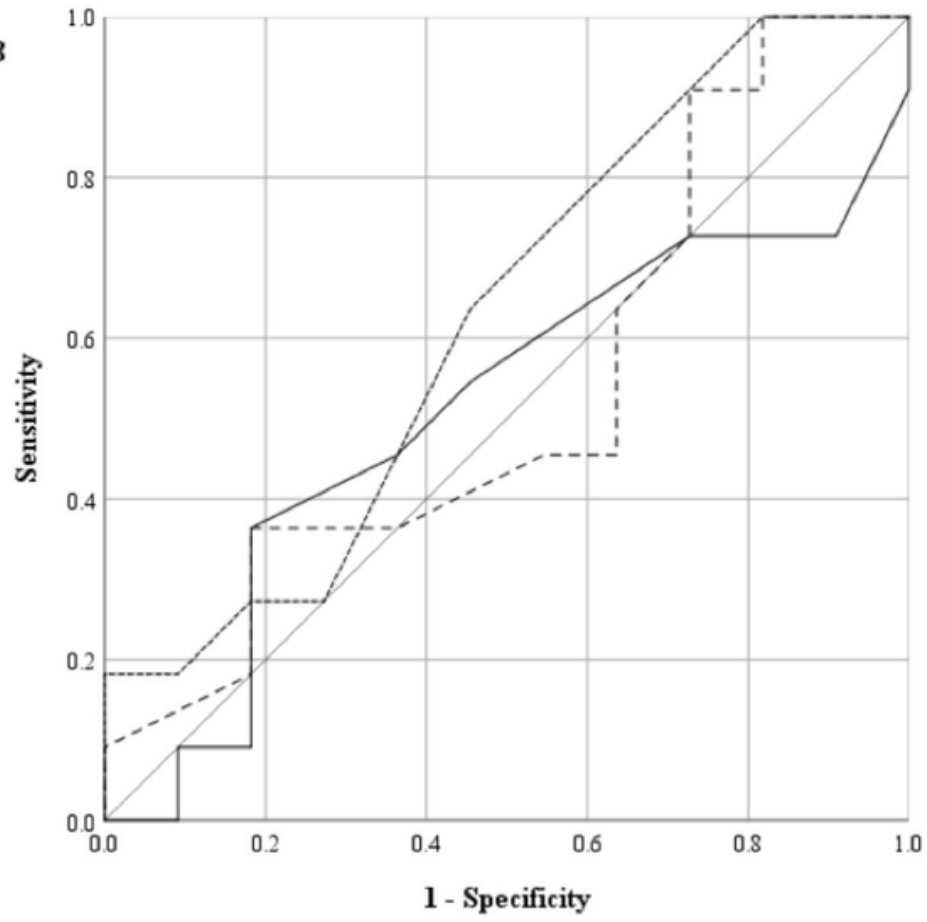

Source of the Curve

---sVV_6 8

-SVV_8_10

---SVV_6_10

- Reference Line

\section{Figure 2}

Receiver operating characteristic curves of pulse pressure variation (A) and stroke volume variation (B) after the tidal volume challenge 